\title{
CARACTERIZAÇÃO DA FASE LÍQUIDA DE FERMENTADO ALCOÓLICO DE REJEITO DE BANANA APÓS DIFERENTES TÉCNICAS DE SEPARAÇÃO SÓLIDO-LÍQUIDO
}

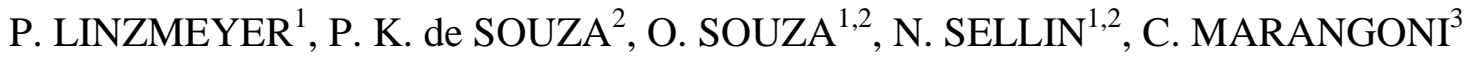 \\ ${ }^{1}$ Universidade da Região de Joinville, Graduação em Engenharia Ambiental e Sanitária \\ ${ }^{2}$ Universidade da Região de Joinville, Mestrado em Engenharia de Processos \\ ${ }^{3}$ Universidade Federal de Santa Catarina, Campus Blumenau \\ E-mail para contato: cintia.marangoni@ufsc.br
}

\begin{abstract}
RESUMO - A produção de etanol a partir de resíduos da bananicultura difere da que utiliza a cana-de-açúcar como biomassa (empregada no Brasil) no que se refere ao uso de frutos rejeitados pois além dos microrganismos, há presença de uma fração de sólidos suspensos conferindo ao caldo menor fluidez. Este trabalho teve por objetivo caracterizar a fase líquida do fermentado utilizando-se três diferentes métodos de separação sólido-líquido (centrifugação, microfiltração e filtração a vácuo). Foram analisados os seguintes parâmetros: concentração de etanol e outros álcoois, açúcares redutores, ânions, carbono, nitrogênio, sólidos voláteis e totais, demanda química de oxigênio, turbidez assim como a massa após o processo. Os resultados apresentaram pequenas diferenças na composição do fermentado quando os processos de microfiltração e filtração a vácuo foram comparados com o convencional (centrifugação), indicando vantagens para a posterior recuperação do etanol.
\end{abstract}

\section{INTRODUÇÃO}

Na busca de substitutos para combustíveis fósseis, cuja utilização vem provocando mudanças climáticas e aquecimento global destacam-se os produzidos com base em matéria orgânica renovável. Diferentes biomassas provenientes de resíduos lignocelulósicos estão sendo avaliadas mundialmente, tais como os subprodutos florestais, resíduos de papel, de madeira, sorgo sacarino, e resíduos agrícolas (Fischer et al., 2013). Assim, dentro deste escopo, os resíduos da bananicultura, em especial o pseudocaule, as folhas e os frutos rejeitados mostram-se atrativos para a produção de etanol de segunda geração devido ao seu elevado potencial de utilização como matéria-prima de baixo custo e grande oferta. Sua utilização permite a redução da poluição ambiental e agrega valor para o cultivo da banana, que tem sofrido nos últimos anos devido à flutuação do prêmio do produto no mercado interno brasileiro (Fernandes et al., 2013). De fato, estudos mostram que o rendimento e a produtividade em etanol a partir da fermentação de fruto rejeitado, de cascas de banana e de pseudocaule de bananeira são promissores (Gonçalves Filho et al., 2013; Souza et al., 2012).

O processo de produção de etanol a partir de resíduos da bananicultura difere do qual utiliza a cana-de-açúcar como biomassa (largamente empregado no Brasil), principalmente quando se refere à polpa de frutos rejeitados, em que estes são incluídos in natura no caldo fermentativo, pois além das 


\section{9 a 22 de outubro de 2014 \\ Florianópolis/SC}

células nativas e inativas das leveduras, há a presença de uma fração de sólidos suspensos, o que confere ao caldo menor fluidez. Além disso, o caldo fermentado a partir de resíduos lignocelulósicos contém não apenas etanol, açúcares e sais, mas também teores de óleo e de sólidos em suspensão que podem influenciar posteriormente a eficiência do processo de recuperação do etanol (Zhang et al., 2012). Na sequência de pré-tratamento e de hidrólise enzimática da biomassa lignocelulósica, ou mesmo no caldo fermentado diretamente com resíduos, os sólidos residuais estão presente em concentrações elevadas e possuem uma distribuição de tamanho de partículas ampla. Estes sólidos, que podem ser difíceis de remover da solução, têm um impacto prejudicial sobre as fermentações bem como na etapa posterior de separação do etanol.

A clarificação do caldo fermentativo é efetuada normalmente realizada por centrifugação, método conhecido como convencional e atualmente bem estabelecido. Porém, visando a otimização do processo e a redução da energia empregada, propostas vem sendo apresentadas como alternativas a forma clássica de separação de sólidos. A fim de melhorar a qualidade do álcool produzido, reduzir o consumo de energia e também o custo de tratamento de efluentes, é importante avaliar o método de separação dos sólidos do caldo fermentado. Leveduras floculantes têm sido utilizadas a fim de facilitar a recuperação de biomassa em processos que operam continuamente por um longo período de tempo (Zhao e Bai, 2009). Um método de pré-tratamento com floculação utilizando quitosana e alginato de sódio foi utilizado por Gao et al. (2013) para facilitar a filtração posterior visando a recuperação de ácidos presentes no caldo fermentado. Agentes de floculação como polieletrólitos podem ser usado para melhorar a clarificação sólido-líquido de biomassa lignocelulósica conforme demonstrado por Burke et al. (2011). A possibilidade de utilizar hidrociclones para separar leveduras foi investigada por Habibian et al. (2008) com o propósito de reduzir o consumo de energia. Processos com membranas também são sugeridos e exemplos são os estudos de Bello et al. (2012) que empregaram membranas de poliimida para realizar a microfiltração do caldo fermentado ou o de Wojciech et al. (2013) que utilizaram microfiltração tangencial do mosto fermentado de um processo de sacarificação e fermentação simultânea. Apesar do foco principal destes estudos serem a redução do consumo de energia ou a otimização na recuperação de um determinado componente, observa-se que o método empregado pode alterar a composição e as características da corrente que será posteriormente utilizada recuperação do etanol. Assim, o objetivo deste trabalho consistiu na avaliação de três métodos de separação diferentes (centrifugação, microfiltração e filtração a vácuo) visando caracterizar as frações líquidas resultantes. Devido as característica do caldo fermentado obtido a partir de frutos rejeitados de banana, faz-se necessária a avaliação do método de separação sólido-líquido utilizado a fim de identificar se este interfere na composição do caldo que será direcionado para as colunas de destilação fracionada.

\section{METODOLOGIA}

\subsection{Fermentação}

O caldo fermentado utilizado nos ensaios de separação foi obtido em biorreator, contendo $3 \mathrm{~L}$ de volume de trabalho e $20 \%$ v/v de inóculo, onde empregou-se a levedura Saccharomyces cerevisiae e polpa de banana rejeitada in natura na concentração de substrato de $500 \mathrm{~g} \mathrm{MU} \mathrm{L}^{-1}$. As fermentações foram conduzidas a $30^{\circ} \mathrm{C}$ por $12 \mathrm{~h}$ e agitação com frequência de $150 \mathrm{~min}^{-1}$. 


\section{9 a 22 de outubro de 2014 \\ Florianópolis/SC}

\subsection{Separação sólido-líquido}

Os ensaios de centrifugação foram conduzidos a $3800 \mathrm{~min}^{-1}$, durante 20 minutos em centrífuga refrigerada, modelo 280-R (Excelsa 4). Após a centrifugação, o sobrenadante foi imediatamente retirado e as frações sólida e líquida congeladas para posterior análise. Nos ensaios de filtração a vácuo, o caldo fermentado foi alimentado em um funil de Buchner contendo papel filtro e conectado a um Kitassato. A esse conjunto foi acoplado a bomba de vácuo DV 142N 250 (J/B Industries) para a redução da pressão. Realizou-se o ensaio em temperatura ambiente durante um período de aproximadamente $5 \mathrm{~h}$. Para os ensaios de microfiltração, o caldo fermentado foi alimentado em temperatura ambiente por bomba de engrenagens FE 611 (B. Braun) com vazão de 90 L/h. O módulo de microfiltração utilizado é fabricado em PVC e possui em seu interior membranas ocas de poli(imida), com área total de $0,08 \mathrm{~m}^{2}$. Os experimentos foram realizados em bateladas com duração de uma hora.

\subsection{Análises realizadas}

Identificação e quantificação dos componentes presentes na fase líquida do caldo após processo de separação foram realizadas por cromatografia gasosa, com o equipamento da Agilent, modelo 6890, acoplado com amostrador automático (Agilent, modelo 7683) e coluna da Hewlett-Packard HP-1 de comprimento $50 \mathrm{~m}$ e diâmetro externo de $0,32 \mathrm{~mm}$, com fase estacionária de $100 \%$ polidimetilsiloxano e espessura de filme $1,05 \mu \mathrm{m}$ tendo o hélio com fluxo de $2,2 \mathrm{~mL} \cdot \mathrm{min}^{-1}$ como eluente. Também foi utilizada Cromatografia líquida de alta eficiência, empregando cromatógrafo Merck Hitachi D-7000 IF equipado com detector de índice de refração (Merck RI-71). Como eluente foi utilizado $\mathrm{H}_{2} \mathrm{SO}_{4}$ na concentração de $8,5 \mathrm{mM}$ e fluxo de $0,5 \mathrm{mLmin}^{-1}$. Para seleção dos componentes a serem avaliados, utilizou-se os trabalhos de Bessa et al. (2012) e Batista \& Meirelles (2011), onde álcoois, aldeídos, ácidos orgânicos e outros coprodutos de fermentação foram identificados em um processo industrial de produção de etanol.

Para determinação de açúcares redutores (AR) utilizou-se o método colorimétrico proposto por Somogyi-Nelson (Somogyi, 1952; Nelson,1944), onde adicionou-se a 500 $\mu 1$ da amostra já diluída o reativo Somogy $(500 \mu \mathrm{l})$. A mistura foi deixada em banho-maria a $100^{\circ} \mathrm{C}$ por $10 \mathrm{~min}$, e após resfriar, foi adicionado $500 \mu \mathrm{L}$ de reativo de Nelson e $3,5 \mathrm{~mL}$ de água destilada, com agitação vigorosa. A leitura de absorbância foi efetuada em espectrofotômetro LKB BIOCHROM, Novaspec II, com comprimento de onda $540 \mathrm{~nm}$. O valor de AR foi determinado a partir da Equação 1 obtida de uma curva de calibração utilizando soluções aquosas de glicose nas concentrações de 0,02 a $0,10 \mathrm{mg} / \mathrm{mL}$.

$$
A b s=6,1735 A R-0,0173
$$

Também foram determinados: Nitrogênio Total (NT) através da metodologia proposta pela Hach, segundo Manual de Instrução Hach Company; Demanda Química de Oxigênio (DQO) estimada empregando-se Kit DQO Reagente da Hach, na faixa de 0 a $1500 \mathrm{mg} \mathrm{O}_{2} \mathrm{~L}^{-1}$ seguindo metodologia proposta pelo mesmo fornecedor; concentrações de Sólidos Totais (ST) que foram realizados através de análises gravimétricas empregando cadinhos de porcelana previamente secos em estufa $\left(105{ }^{\circ} \mathrm{C}\right.$, 
durante 48 horas) até massa constante, Carbono Total (CT) e carbono inorgânico utilizando um analisador de carbono orgânico total. Para a identificação e quantificação dos ânions, as amostras foram previamente diluídas, posteriormente filtradas em filtro de $0,45 \mu \mathrm{m}$ e analisadas em Cromatógrafo de Íons, coluna 1523 e pré-coluna AG23. A turbidez foi determinada com o turbídimetro Turbiquanti 1100 IR (Merck). Os sólidos voláteis foram estimados através de análises gravimétricas, empregando calcinação em mufla $\left(550 \pm 50^{\circ} \mathrm{C}\right.$, por 1 hora $)$.

\section{RESULTADOS}

Na Figura 1 é apresentada a comparação da massa resultante das fases líquida e sólida em relação ao total gerado no processo fermentativo. Quando o processo empregado foi a centrifugação, menor quantidade de massa na fase sólida foi gerada (cerca de $29 \%$ do total), indicando melhor rendimento em fase líquida (aproximadamente 71\% do total). Este comportamento é observando de forma inversa para os processos de microfiltração e filtração a vácuo, onde menor quantidade em massa de fase líquida foi obtida em virtude da própria natureza destes processos. Do ponto de vista da quantidade de resíduo gerado (fase sólida), o processo de centrifugação é mais interessante uma vez que gera menor quantidade de material que será descartado.

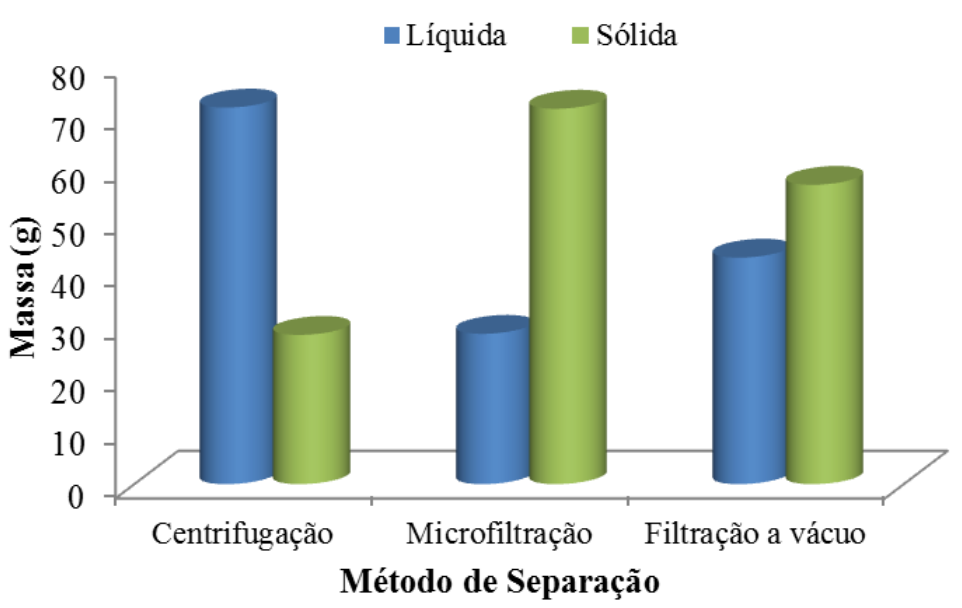

Figura 1 - Comparação entre a quantidade em massa gerada nas fases líquida e sólida após o emprego dos processos de centrifugação, microfiltração e filtração a vácuo no caldo fermentado.

A caracterização da composição do caldo fermentado a partir de frutos rejeitados de banana e posterior emprego dos processos de separação é apresentada na Tabela 1. Através das análises cromatográficas, além do etanol, identificaram-se em maior quantidade sete componentes provenientes do processo fermentativo com a polpa de banana. Segundo Bessa et al. (2012), os componentes identificados neste trabalho estão entre os frequentemente citados na literatura para fermentações alcoólicas. No entanto, o número de compostos foi reduzido em relação ao apresentado na literatura. Boscolo et al. (2000) descreve que para a obtenção da cachaça brasileira são gerados na fermentação mais de 51 compostos entre álcoois e ésteres. Dessa forma, observa-se então que o emprego do fruto rejeitado diretamente na fermentação pode ter implicado em modificações na 

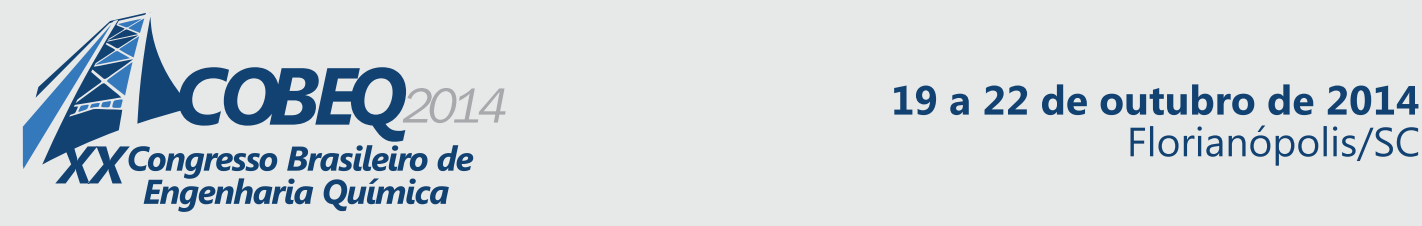

Florianópolis/SC

presença dos componentes do caldo fermentado. Uma vez que os mesmos componentes foram encontrados, independente do método de separação empregado, atribui-se este comportamento a realização do processo ao substrato utilizado ou a produção em escala laboratorial.

Um fator relevante é a concentração de etanol e subprodutos, os quais diferem dos valores apresentados pelos autores pesquisados. Ressalta-se que os trabalhos utilizados para comparação também visaram a produção de etanol, e não de bebidas alcóolicas como muito apresentado na literatura. Considerando que os autores citados na Tabela 1 utilizaram dados de caracterização de fermentações em escala industrial, processo de separação convencional, bem como diferentes substratos como a cana-de-açúcar e uva respectivamente, pode-se inferir que a produção destes compostos no processo de fermentação alcoólica está diretamente relacionada ao substrato utilizado na fermentação. Esta observação também é corroborada por Dragone et al. (2009) que caracterizou o caldo fermentado a partir de soro de leite visando a produção de bebidas alcóolicas.

Tabela 1 - Composição (base volumétrica) do caldo fermentado a partir de fruto rejeitado de banana após os processos de separação empregados: comparação com a literatura.

\begin{tabular}{|l|c|c|c|c|c|}
\hline \multirow{2}{*}{ Componente } & \multicolumn{3}{|c|}{ Neste trabalho } & Batista e & Bessa et al. \\
\cline { 2 - 6 } & Centrifugação & Microfiltração & $\begin{array}{c}\text { Filtração a } \\
\text { vácuo }\end{array}$ & $\begin{array}{c}\text { Meires } \\
(2011)\end{array}$ & \begin{tabular}{c} 
(2012) \\
\hline Etanol (\%)
\end{tabular} \\
\hline Isobutanol (\%) & 3,643 & 2,973 & 3,073 & 6,6 & 8,1 \\
\hline Metanol (\%) & 0,005 & 0,005 & 0,005 & 0,00278 & 0,00278 \\
\hline Pentanol (\%) & 0,023 & 0,016 & 0,020 & 0,000032 & 0,000032 \\
\hline Propanol (\%) & 0,017 & 0,007 & 0,006 & - & 0,0001 \\
\hline Ácido acético (\%) & 0,006 & 0,004 & 0,004 & 0,00336 & 0,003 \\
\hline Ácido succínico (\%) & 0,045 & 0,013 & 0,013 & 0,04351 & - \\
\hline Álcool isoamílico (\%) & 0,022 & 0,023 & 0,023 & - & - \\
\hline
\end{tabular}

Entre os processos de centrifugação, filtração a vácuo e microfiltração, pode-se observar que as percentagens mássicas de etanol para os três processos foram semelhantes, sugerindo assim que o método de separação não influencia a recuperação do produto em questão. Entretanto, os componentes ácido acético e pentanol apresentaram valores menores para os processos de microfiltração e filtração a vácuo. Esta é uma questão vantajosa uma vez que tais componentes tem uma quantidade máxima estabelecida por órgãos reguladores para o uso de etanol como combustível. Gamboa et al. (2012) afirma que as diferentes composições físico-químicas das vinhaças citadas em seu trabalho são atribuídas não somente as matérias-primas utilizadas mas também aos processos inerentes a cada substrato utilizado para obtenção do etanol de segunda geração. Acredita-se então, que os componentes encontrados em menor quantidade nos processos de microfiltração e filtração a vácuo possam estar adsorvidos na massa sólida retida na membrana da unidade de microfiltração e no papel filtro do ensaio de filtração a vácuo. 


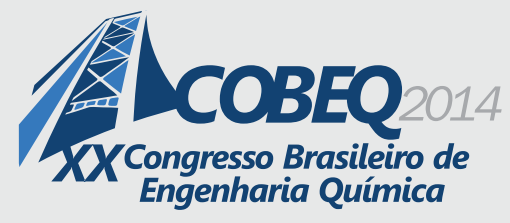

19 a 22 de outubro de 2014
Florianópolis/SC

Na Tabela 2 são apresentados os resultados das análises de açúcares redutores (AR), demanda química de oxigênio (DQO), nitrogênio total (NT), sólidos totais (ST), sólidos voláteis (SV), carbono total (CT), carbono inorgânico (CI) e turbidez para a fração líquida após o emprego dos processos de separação de centrifugação, microfiltração e filtração a vácuo. Menores concentrações de nitrogênio total e de carbono total foram encontradas com os processos de microfiltração e filtração a vácuo. Tendo em vista que estes dois sistemas apresentam uma barreira física, membrana e papel filtro, e que o nitrogênio pode ser encontrado não somente sob a forma de gás dissolvido, mas também em combinações inorgânicas e orgânicas, acredita-se que o nitrogênio esteja presente na fração sólida separada. Por outro lado, a maior concentração de carbono inorgânico foi encontrada justamente nestes processos (microfiltração e filtração a vácuo), indicando menor separação destes componentes. O mesmo comportamento foi visualizado para a quantificação de açúcares redutores e DQO.

Para a clarificação do caldo, observa-se que o melhor resultado foi o obtido com a microfiltração, pois apresenta a maior remoção de sólidos totais entre os demais processos estudados (cerca de $30 \%$ a menos que a centrifugação e $12 \%$ em relação a filtração à vácuo), verificando-se assim maior potencialidade no processo de separação de líquidos e sólidos. Além disso, as condições operacionais da microfiltração também são atrativas, podendo proporcionar um sistema de fluxo contínuo de separação de sólidos. Este resultado também é evidenciado por meio da análise de turbidez onde a fase líquida obtida por microfiltração possui um índice de turbidez que corresponde a apenas $2 \%$ do total obtido com centrifugação e $6 \%$ em relação a filtração à vácuo.

Tabela 2 - Caracterização da fração líquida do caldo fermentado obtido a partir de fruto rejeitado de banana e separado por centrifugação, microfiltração e filtração a vácuo.

\begin{tabular}{|l|c|c|c|}
\hline Parâmetro & Centrifugação & Microfiltração & Filtração a vácuo \\
\hline ART (mg/L) & $3.346,6$ & $14.912,1$ & $1.402,8$ \\
\hline DQO (mg/L) & 8.8200 & 132.300 & 58.400 \\
\hline NT (mg/L) & 177 & 96 & 80,1 \\
\hline ST $(\mathrm{mg} / \mathrm{L}) \mathrm{x}$ & 17.737 & 12.923 & 14.715 \\
\hline SV $(\mathrm{mg} / \mathrm{L})$ & 3.774 & 561 & 740 \\
\hline CT $(\mathrm{mg} / \mathrm{L})$ & 793 & 631,9 & 616,3 \\
\hline CI (mg/L) & 0,3285 & 0,4120 & 0,3446 \\
\hline Turbidez $(\mathrm{NTU})$ & 614,5 & 14,07 & 205,9 \\
\hline
\end{tabular}

$\mathrm{Na}$ Tabela 3 são resumidos os resultados obtidos para quantificações dos íons presentes na fase líquida para os três métodos de separação empregados. Não foi observada uma tendência uniforme de um método que apresente todos os índices analisados em maior ou menor quantidade em relação aos outros. Do ponto de vista de que a fase líquida resultante será enviada a um processo de separação (normalmente destilação), e entendendo que a presença de íons pode ser analisada como uma forma de avaliação da quantidade de sais presentes, seria interessante que estes estivessem presentes em menor quantidade visando evitar problemas tais como corrosão. Também, determinados processos de separação por membranas como pervaporação possuem melhor eficiência na ausência de sais. Neste 
sentido, de uma forma ampla, pode-se analisar que microfiltração e filtração a vácuo apresentaram resultados inferiores à centrifugação para todas as análises realizadas, com exceção de fluoretos, fosfatos e sulfatos.

Tabela 3 - Caracterização de íons presentes na fração líquida do caldo fermentado obtido a partir de fruto rejeitado de banana e separado por centrifugação, microfiltração e filtração a vácuo.

\begin{tabular}{|l|c|c|c|}
\hline Íons & Centrifugação & Microfiltração & Filtração a vácuo \\
\hline Fluoreto $(\mathrm{mg} / \mathrm{L})$ & 9,6719 & 138,7579 & 64,9368 \\
\hline Cloreto $(\mathrm{mg} / \mathrm{L})$ & 1315,669 & 1066,2128 & 1049,7364 \\
\hline Nitrito $(\mathrm{mg} / \mathrm{L})$ & 84,6612 & - & - \\
\hline Brometo $(\mathrm{mg} / \mathrm{L})$ & 25,5821 & - & - \\
\hline Nitrato $(\mathrm{mg} / \mathrm{L})$ & 605,5102 & 185,0716 & 143,6861 \\
\hline Fosfato $(\mathrm{mg} / \mathrm{L})$ & - & 459,2856 & 499,351 \\
\hline Sulfato $(\mathrm{mg} / \mathrm{L})$ & 1432,759 & 2317,8004 & 2231,0547 \\
\hline
\end{tabular}

\section{CONCLUSÕES}

Neste trabalho, constatou-se que na comparação entre o processo clássico de centrifugação com os processos de filtração a vácuo e microfiltração para a separação líquido-sólido do caldo fermentado a partir do fruto rejeitado de banana, que não houve diferença representativa na composição do caldo clarificado. As diferenças observadas devido a presença ou não de um componente bem como suas concentrações são atribuídas ao substrato utilizado, e esta consiste em uma das contribuições deste trabalho.

O tratamento do caldo fermentativo por microfiltração apresentou maior potencialidade em relação à centrifugação e filtração a vácuo para a separação dos sólidos totais na fase líquida, bem como para os outros parâmetros analisados. Mesmo tendo apresentado menor rendimento em fase líquida, o processo mostrou-se uma alternativa bastante atrativa em relação ao método convencional uma vez que permite que a massa gerada apresente características que favorecem processos de separação comumente aplicados para a recuperação do etanol (fase seguinte na cadeira produtiva).

\section{REFERÊNCIAS}

BATISTA, F. R. M.; MEIRELLES, A. J. A. Computer simulation applied to studying continuous spirit distillation and product quality control. Food Control, v. 22, p. 1592-1603, 2011

BELlO, R. H., SOUZA, O., SELliN, N., MEDEIROS, S. H. W., MARANGONI, C. Effect of the microfiltration phase on pervaporation of ethanol produced from banana residues. Comput.-Aided Chem. Eng. v. 31, p. 820-824, 2012.

BESSA, L. C. B. A, BATISTA, F. R. M., MEIRELlES, A. J. A. Double-effect integration of multicomponent alcoholic distillation columns. Energy, v. 45, p. 603-612, 2012. 
BOSCOLO, M.; BEZERRA,C. W. B.; CARDOSO, D. R. Identification and dosage by HRGC of minor alcohols and esters in Brazilian sugar-cane spirit. J. Braz. Chem. Soc., v. 11, p. 86-90, 2011.

BURKE, D. R., ANDERSON, J., GILCREASE, P. C., MENKHAUS, T. J. Enhanced solid-liquid clarification of lignocellulosic slurries using polyelectrolyte flocculating agents. Biomass Bioenergy v. 35, p. 391-401, 2011.

DRAGONE, G., MUSSATTO, S. I., OLIVEIRA, J. M., TEIXEIRA, J. A. Characterisation of volatile compounds in an alcoholic beverage produced by whey fermentation. Food Chem., v. 112, p. 929935, 2009.

FERNANDES, E. R. K., MARANGONI, C., SOUZA, O., SELliN, N., Thermochemical characterization of banana leaves as a potential energy source. Energy Convers. Manage., v. 75, p. 603-608, 2013.

FISCHER J., LOPES V. S., GALVÃO C. M. A., TEODORO J. C., COUTINHO U. F., CARDOSO V. L. Utilization of Cheese Whey and Cellulosic Biomass for Production of Ethanol by Selected Fungi Strain from Brazilian Savannas, Chem. Eng. Trans., v. 32, p. 1075 - 1080, 2013

GAMBOA E. E., CORTES J. M., PEREZ L. B., MALDONADO J. D., ZARATE G. H., GAVIRIA L. A. Vinasses: characterization and treatments, Waste Manage. Res., v. 29, p. 1235-1250, 2011

GAO, Q., DUAN, Q., WANG, D., ZHANG, Y., ZHENG, C. Separation and purification of $\gamma$ aminobutyric acid from fermentation broth by flocculation and chromatographic methodologies. $J$. Agric. Food Chem.,v. 61,p. 1914-1919, 2013

GONÇALVES FILHO, L. C., FISCHER, G. A. A., SELlin, N., MARANGONI, C., SOUZA, O. Hydrolysis of Banana Tree Pseudostem and Second-Generation Ethanol Production by Saccharomyces Cerevisae. J. Environ. Sci. Eng. A,v. 2, p. 65-69, 2013.

HABIBIAN, M., PAZOUKI, H., GHANAIE, K., ABBASPOUR-SANI, M. Application of hydrocyclone for removal of yeasts from alcohol fermentations broth. Chem. Eng. J., 138, 30-34, 2008.

NELSON, N. A photometric adaptation of Somogyi method for determination of glucose. Biochemistry, v. 153, p. 375-380, 1944.

SOMOGYI, M. Notes on sugar determination. J. Biol. Chem., v. 195, p. 19, 1952.

SOUZA O., SCHULZ, M. A., FISCHER, G. A. A., WAGNER, T.M, SELLIN, N. Energia alternativa de biomassa: Bioetanol a partir da casca e da polpa de banana, Revista Brasileira de Engenharia Agrícola e Ambiental, v. 16, p. 915-921, 2012.

ZHAO, X.Q., BAI, F.W. Yeast flocculation: New story in fuel ethanol production. Biotechnology Advances, v. 27, p. 849-856, 2009.

ZHANG, W., MA, H., WANG, Q., ZHAO, F., XIAO, Z. Pretreatment technology for suspended solids and oil removal in an ethanol fermentation broth from food waste separated by pervaporation process Desalination, v. 293, p. 112-117, 2012. 